\title{
HABITAT PREFERENCES OF THE PHILIPPINE TARSIER (TARSIUS SYRICHTA L.) IN LOBOC, BOHOL, PHILIPPINES
}

\author{
TEOFANES A. PATINDOL. \\ Department of Forest and Wildife Management and Conservation \\ College of Forestry and Natural Resources, Visayas State University \\ Visca, Baybay City, Leyte
}

\section{ABSTRACT}

A study was conducted to describe the habitat preference of the Philippine tarsier in Loboc, Bohol. Description of habitat preference was based on species composition and density of the different layers of the stand, mean height, mean diameter and basal area including physical attributes such as aspect, slope and elevation.

Three habitat variants of the Philippine tarsier were observed in Loboc, Bohol. The first variant was a relatively open thicket with many small-diameter trees and shrubs and dense undergrowths. The second variant was a thicket of tall grasses, many small diameter trees and dense undergrowths growing under a mahogany plantation. The third variant was a thicket of many small diameter trees and shrubs with less evident woody vines and dense undergrowths with limited exposure to direct sunlight and strong wind being situated along gullies.

Preferred habitat of the Philippine Tarsier are small diameter trees as roosting sites and dense undergrowth as a source of insects and small vertebrtaes: which are preferred food of the animal. The presence of crevicess, / which are unique to the limestone environment, serve as "hiding places" to protect the animals from predators.

KEY WORDS: Philippine tarsier. Habitat preferences. Loboc, Bohol 


\section{INTRODUCTION}

The Philippine tarsier (Tarsius syrichta L.) is a small monkey-like animal with the body typically smaller than that of the Philippine common field rat. It is known for its big, round eyes; bat-like ears; and the ability to turn its head almost 360 degrees. It has brownish grey fur and a bald tail, which is twice as long as its body (Rabor, 1977).

In the Philippines, the tarsier can be found in decreasing numbers on the islands of Bohol, Leyte, Mindanao and Samar. Like all species of tarsier, it is crepuscular and nocturnal in habit. It stays at the edges and right inside dense vegetation of different types, including patches of dipterocarp forest and secondary forest preferably among dense bushes and low under growths. Occasionally it stays even inside dense bushes that grow at the edges of cogon grasslands in areas, which have been cleared and abandoned to grass (http://arcbc.ph/I).

In 1990, the IUCN declared the Philippine tarsier as threatened and endangered. One main reason for the critically declining population of the species is the destruction of their known forest habitats. Years of commercial logging, slash-and-burn agriculture and illegal logging activities have greatly reduced the forest covers of Bohol, Mindanao, Samar, and Leyte areas where tarsiers are found. Restricted distribution and confinement to tropical forests which have suffered immense degradation, the Philippine tarsier was then considered as "lower risk, conservation dependent". This simply means that it is not yet categorized as vulnerable, endangered, or critically endangered, but it could qualify within five years in one of those categories if present programs to protect the species are stopped. Presently the status of the Philippine tarsier was "data defícient" (IUCN, 2006). 
It is important to study the preferred habitats of tarsiers in Loboc Watershed to help conserve the species being an icon for biodiversity conservation and ecotourism not only for the Municipality of Loboc but for the entire Province of Bohol. Knowledge on specifies composition and site / characteristics of habitats of Philippine tarsier will provide practical bases in formulating and implementing site-specific future strategies with emphasis on habitat manipulation for the conservation of the species.

\section{MATERIALS AND METHODS}

\section{Study Area}

Loboc is a 5th class municipality, $24 \mathrm{~km}$ away from Tagbilaran City, the provincial capital of Bohol. According to the 2000 census, it has a population of 15,734 people in 2,738 households. (http://www.answers.com/topic/loboc-bohol). Loboc has an elevation ranging from 300 to $350 \mathrm{~m}$ asl, a large part of which has a slope of $8-18 \%$ or undulating to rolling plain. It has a land area of 8,541 has. Some parts of Loboc are open and relatively bare, but on the whole vegetation is adequately lush, mostly of second growth trees, bamboo clumps, tall grass patches, and the thick bushes that the tarsiers prefer (http://www. bohol.net/PTFII sanctuary.htm).

The study was conducted in Sitio Sug-ong, Barangay Jimillan, Loboc, Bohol The area is known by most inhabitants of Loboc as the major source of tarsiers for the pet trade for local and foreign tourists and the major supplier for the tourist facilities along Loboc Rivers for tourist exhibition.

The lower slopes of Sug-ong are predominantly alienable and disposable but a big proportion of the upper slopes are part of the public domain. Most lots in the lower slopes are titled while those at the upper slopes are covered with 
stewardship contract under the Integrated Social Forestry Program since the 1980s. Active cultivation in the form of kaingin in the slopes of Sug-ong particularly those facing the Loboc River, was banned since the early 1990 s through a municipal ordinance in support of the tourism industry of the municipality. The vegetation of the area is generally of the early regeneration type that developed after more than a decade of abandonment from active cultivation. A portion of the area, which had been a part of the reforestation project under the Loboc Watershed Rehabilitation Project of the Department of Environment and Natural Resources, was planted to mahogany, the flagship reforestation species in the province since the late 1950 s.

\section{Site Identification}

For the identification of study sites, an ethno-biological survey regarding positive sightings of tarsiers was conducted in Loboc, Bohol with the use of key informant interview and focus group discussion methods.

In the key informant interviews, persons knowledgeable about the place and the tarsiers were interviewed. They were asked on where the tarsiers are mostly seen in the area. Focus-group discussions were also conducted to verify the information given by the key informants.

\section{Structure of Stand}

Species composition, tree density, total height and basal area were used to describe the structure of stand in each site. Nested quadrat method was used to assess the vegetation structure. For each site, three $20 \times 20 \mathrm{~m}$ quadrats were established to describe the tree vegetation. The total height of all trees was determined using an Abney hand level. The diameter at breast height (DBH) of the trees was measured using a tape measure at approximately $1.3 \mathrm{~m}$ above the ground. Basal area was calculated using the formula: $\pi d^{2}$. 
Three $3 \times 3 \mathrm{~m}$ quadrats were established randomly within the randomly selected $20 \times 20 \mathrm{~m}$ quadrat. In each quadrat, the density of saplings (1-3 m.height) was determined by counting the number of sapling inside the quadrat.

Three $1 \times 1 \mathrm{~m}$ quadrat were established randomly within the randomly selected $3 \times 3 \mathrm{~m}$ quadrat. The density of ground layer was determined by counting the number of wildings (seedlings growing in the wild), herbs, shrubs and vines inside the quadrat.

\section{Physical Variables}

Physical variables such as aspect, slope and elevation of the study sites were determined with the use of staff-head compass, Abney hand level and altimeter, respectively.

\section{RESULTS AND DISCUSSION}

\section{Habitat Variants}

Three variants of Philippine tarsier habitats were observed in Loboc, Bohol. These were differentiated based on the stand structure unique in each type and physical attributes such as aspect, slope and elevation (Table 1 and 2). Stand structure was described based on species composition and density of the different layers such as tree layer, sapling and ground layers. Mean height, mean diameter and basal area were also used to compare habitat variability.

The first variant, which was observed in Site 1, was a relatively open thicket with many small-diameter trees and shrubs and dense undergrowths. The site is facing east where it is directly exposed to the sun. This is the dominant vegetation type in the slopes of Sug-ong and other parts of Jimilian where traces of previous cultivation were very evident because of the relatively open canopy layer (Table 1). 
Table 1. Structure of stand of the different habitat variants of Tarsius syrichta $L$. in Loboc, Bohol c.2006.

\begin{tabular}{llll}
\hline & SITE 1 & SITE 2 & SITE 3 \\
\hline Mean tree diameter (cm) & 6.01 & 5.74 & 5.44 \\
Mean tree height (m) & 5.35 & 4.79 & 5.23 \\
Basal area (m²/area) & 0.2899 & 1.2052 & .2336 \\
Tree Density per hectare & 72 & 211 & 76 \\
Tree Diversity & 24 & 30 & 25 \\
Sapling Density per hectare & 68,888 & 42,222 & 101,111 \\
Sapling Diversity & 23 & 14 & 12 \\
Ground Layer Density per square meter & 71 & 50 & 77 \\
Ground Layer Diversity & 21 & 16 & 20 \\
\hline
\end{tabular}

Site 1 had a mean tree density of 72 and a mean tree diversity of 24 . It has the highest mean tree $\mathrm{DBH}$ of 6.01 and with the highest mean tree vegetation height of 5.35. Vitex parviflora (molave), a tree commonly growing in a limestone substrate and dry places, was observed to have the highest basal area. Small-diameter trees common in the area are Ixora philippinensis (kayomkom), Dysoxylum arborescens (kalimutain), Xylopia dehiscens (sudkad), Litsea oblongifolia (ingas) and Buchanania arborescens (balinghasay). Carallia brachiata (bakauan gubat) had the highest density for saplings. Other saplings with high density are Terminalia microcarpa (kalumpit) and Ficus irisana (aplas). Site 2 also had the second highest ground layer density of 71. Commonly associated vines, herbs and wildings observed are Cyperus sp., Enythropyllum sp., Scleria scrobiculata (sarat), and Heterospathe elata (sagisi).

The second variant was observed in site 2 facing the southeast direction. It is a thicket of tall grasses, few medium-seized trees, many small diameter trees and dense undergrowths. It is located within an abandoned mahogany plantation. 
Swietenia macrophylla (mahogany) had the highest basal area. The tarsiers however do not use the mahogany for locomotion because it does not provide suitable material for the tarsier. The dense undergrowths beneath the mahogany trees are the preferred habitat for tarsiers. Site 2 had the highest basal area of 1.20 . This is primarily due to the presence of the mahogany, the main reforestation species. It also had the highest tree density of 211 and highest tree diversity of 30 . Naturally occurring small-diameter trees are Buchanania arborescens, Mallotus philipensis (banato), Ixora philippinensis (kayomkom), Carallia brachiate (bakauan gubat), and Terminalia microcarpa (kalumpit).

Arundo donax (giant reed), a tall grass is common in the area as compared with the other two sites. According to Reyes (2006), its drooping bunch of culms serves as cover and den of the tarsier. Compared to the other sites, site two had the lowest sapling density and ground layer density due to the presence of many mahogany trees, which could restrict the amount of sunlight reaching into the ground. This condition prevents the growth of saplings. On the other hand, the ground layer diversity is lowest in this site because it is dominated mostly by Arundo donax.

The third variant is Site 3 characterized by a thicket of many small diameter trees and shrubs with less woody vines and dense undergrowths. It is located in a south-facing gully where it receives direct sunlight during noontime only because of topographic barriers in the eastern and western sides. It is darker and cooler in this site compared to the other two on account of the shading effect of the topographic barriers. Water also collects and drains through the site being situated in gullies. Aside from the dark condition, the site is also protected from strong wind because of the topographic barriers. Tarsiers are highly sensitive to wind movement as reported by local residents during the interview and focus group discussion. This could be one of the reasons why Tarsiers prefer the site as roosting area since it is less exposed to strong wind. 
Another differentiating characteristic of this site is the dominance of Ficus irisana (aplas) over other plant species. Commonly associated small diameter trees include: Clerodendron menahassae (bagawak), Litsea bulusanensis (lauat), and Carallia brachiate (bakauan gubat). Most of the tree species are shade tolerant. Vines such as Lygodium sp. are less evident while Selaginella $\mathrm{sp}$. is common in this habitat variant. Site 3 had the highest sapling density and ground layer density.

\section{Common Habitat Elements}

The study shows that most of the tree species recorded had diameters ranging from $4-6 \mathrm{~cm}$. This shows that tarsiers prefer small diameter trees as habitat as was reported by Reyes (2006) and Neri-Arboleda, et al. (2002).

Such structure provides locomotor supports for the tarsiers. The close distance in between trees appears to be a necessary condition which favors the locomotive behaviour of the tarsiers thus enabling them to have a firm grasp of the small trunks and branches. Leaping from one tree to another, in this case, is effortless as reported by Neri-Arboleda, et al. (2002) (Table 2).

Table 2. Physical variables in the different habitat variants of Tarsius syrichta $L$. in Loboc, Bohol c. 2006.

\begin{tabular}{lccc}
\hline PHYSICAL VARIABLES & SITE 1 & SITE 2 & SITE 3 \\
\hline Aspect & East & South east & South \\
Slope $\left({ }^{\circ}\right)$ & $19-22$ & $31-35$ & $26-30$ \\
Elevation (m asi) & $80-115$ & $120-150$ & $110-135$ \\
\hline
\end{tabular}


The small diameter trees such as the Evodia pergamentacea (Plate 1) including the grass Arundo donax (Plate 2) and the palm Heterospathe elata (Plate 3) also provide cover for the tarsier during the day when they are inactive and vulnerable to predators. The dense undergrowths may also provide many insects which is the main diet of the tarsiers.

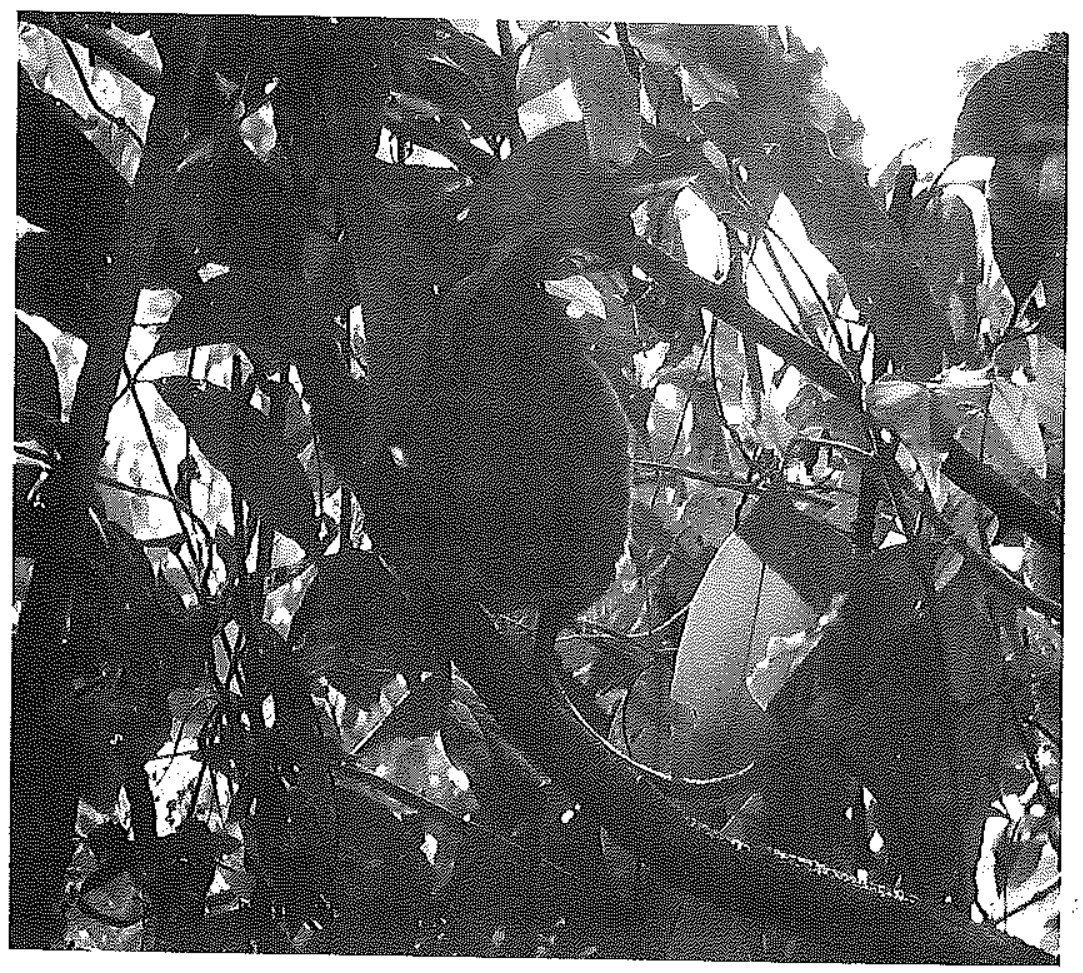

Plate 1. Evodia pergamentacea (tonggamos), one of the common species associated with the limestone areas provides cover for the tarsier during the day when they are inactive and vulnerable to predators. 


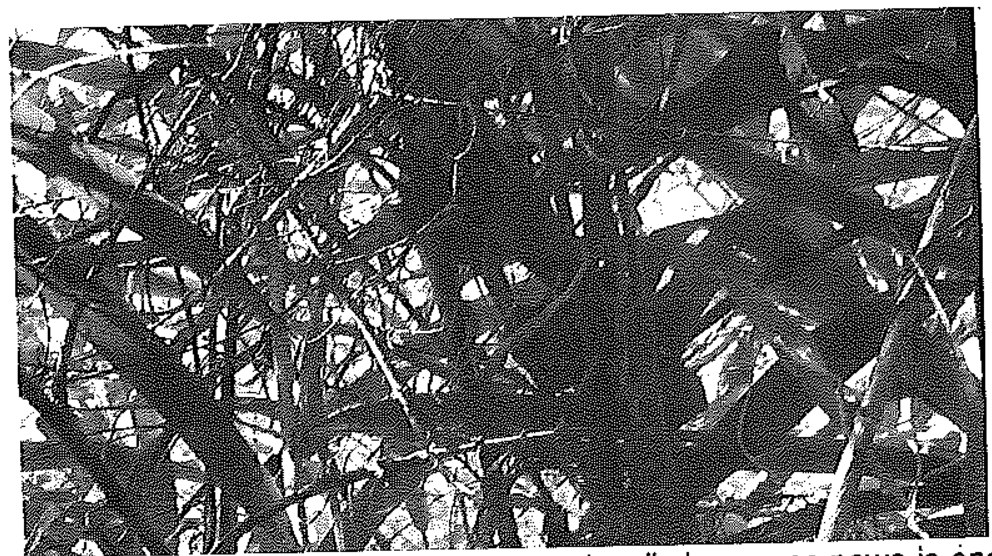

Plate 2. Arundo donax (giant reed), a tall grass locally known as pawa is one of the plant species that provide cover for the tarsier during the day when they are inactive and vulnerable to predators.

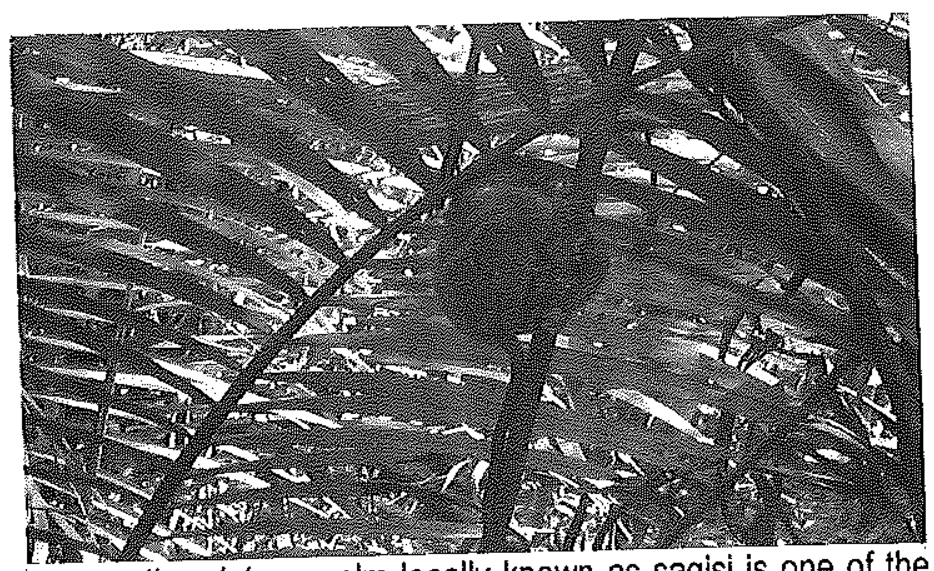

Plate 3. Heterospathe elata, a palm locally known as sagisi is one of the plant species that provide cover for the tarsier during the day when they are inactive and vulnerable to predators. 
Large limestone crevices were observed in all sites (Plate 4). Tarsiers use these crevices including tree holes as retreats when in danger or during heavy rain (Pizzaras, personal communication, 2006).

Presence of water bodies is also an integral element of the habitat of tarsiers. This could be the reason why many tarsier collectors claimed that the third variant harbors more individuals than the two other variants because this variant in gullies where water collects and drains regularly. Key informant interviews further revealed that tarsiers would frequently go to the Loboc River from the upper slopes of Jimilian to drink water during dry months. This is in contrary to Pizzaras' statement that tarsiers stay away from creeks or rivers but may be true as PAWB-DENR (1992) as cited by Reyes (2006) stressed that the .primate was also used to be common in coastal forest near rivers and creeks.

\section{CONCLUSION}

It appears the Philippine tarsier is dependent on these small diameter trees for locomotion and support and undergrowths that support a wide variety of insects and small vertebrates which are considered as food for the tarsiers. The presence of crevices, which are unique to the limestone environment, can further explain close affinity of the creature to the limestone areas.

Determination of the types of habitat of tarsiers and the composition of its habitat provides additional information which could help in further understanding the behaviour and biology of tarsiers especially when they are in the wild and not inside cages. This also helps in making sound decisions for the conservation of the primate's habitat and eventually the species.

\section{LITERATURE CITED}

http://arcbc.org.ph/l. ASEAN Regional Centre for Biodiversity Conservation. Accessed; March 1, 2006. 
http://www.bohol.net/PTFI/sanctuary.htm. The Philippine Tarsier. Foundation, Inc. Accessed: July 16, 2006.

IUCN. 2004: Threatened list of endangered species. http://www, iucnredlist.org/tarsius syrichta derived on January 23, 2007.

IUCN. 1990. Threatened list of endangered species. http://www, iucnredlist.org/tarsius syrichta derived on January $23,2007$.

IUCN 2006. 2006 IUCN Red List of Threatened Species. www.lucnredlist.org. Derived on February 5, 2007.

NERI-ARBOLEDA, I. P., SCOTT and N. P. ARBOLEDA. 2002. Home ranges, spatial movements and habitat association of the Philippine tarsier (Tarsius syrichta L.) in Corella, Bohol. Journal of Zoology: London. 257:387-402

PIZZARAS, CARLITO, 2006. Personal Communication. Philippine Tarsier Foundation, Inc. (PFTI), Corella, Bohol, Philippines.

RABOR, DIOSCORO. S. 1977. Birds and Mammals. UP Press Diliman, Quezon City. pp.234-237

REYES, TOMAS. D. JR. 2006. Plant-environment relation in the Philippine tarsier (Tarsius syrichta L.) habitat. Master's Thesis. Wageningin University and Research Centre, Netherlands. www.lobocbohol.gov.ph-Home. Accessed: July 1, 2006.

\section{ACKNOWLEDGMENT}

The author would like to express his profound gratitude to Honeylene $G$. Valenzona and Czarina L. Platino for their kind assistance during the data collection. 